\title{
Stepwise Modularization in the Construction Industry Using a Bottom-Up Approach
}

\author{
Anders Kudsk ${ }^{1, *}$, Martin O’Brien Grønvold ${ }^{2}$, Magnus Holo Olsen ${ }^{2}$, Lars Hvam² and \\ Christian Thuesen ${ }^{2}$ \\ ${ }^{I}$ Technical University of Denmark - Department of Management Engineering and NCC Construction Denmark; \\ ${ }^{2}$ Technical University of Denmark - Department of Management Engineering, Denmark
}

\begin{abstract}
The manufacturing industry has experienced a great deal of improvement in efficiency and cost reductions throughout the last centuries. But although there have been improvements in the manufacturing industry, the principles and work methods in the construction industry have stood still for more than a hundred years. Based on principles of mass customization applied in the manufacturing industry, two cases of successful implementation of mass customization and modularization have been investigated as a means of showcasing the possibility to incorporate standardization in parts of the construction industry. The investigation examined two different companies that have standardized parts of a construction. One, Altan.dk, standardized the method for constructing balconies; and NCC Skakt standardized the construction of shafts.

Altan.dk standardized their balconies by studying the balconies they previously built and constructing solution spaces in which a configured balcony can be constructed. The information gathered from studying these balconies was then put into a Product Variant Master, so that an overview of the product was achieved. All the information gathered was put into a configurator in order to guide the entire construction process.

NCC Skakt standardized their shafts by studying apartments already constructed and extracting different archetypes of toilets and kitchens. Much information was gathered, which was fed into a Product Variant Master, so that an overview could be achieved. This led to a standardization of the shafts. Three types of shafts that make up 95 percent of the investigated market were defined.

Based on the findings and experiences gathered through the standardization, it is concluded that the principles of mass customization of a sub-part can be successful when implemented stepwise. The case shows that substantial benefits can be gained through implementing modularized construction. It is especially interesting to note that these benefits are achieved through the development of a module with focus on the internal interfaces.
\end{abstract}

Keywords: Configuration, construction, modularization, bottom-up modularization, product variant master, stepwise implementation.

\section{INTRODUCTION}

Some industries, primarily manufacturing, have achieved significant efficiency improvements by offering customized products that are not designed and produced as unique products, but rather selected and composed within a predefined range, through mass customization, product architecture, modularization and configuration [1-5].

The construction industry, however, goes the other way. Attempts have previously been made to produce mass construction elements that can be used as a basis from which mass customization takes place (see Fig. 1). This method differs from traditional mass production in that the customer, within a range of pre-specified boundaries, has the

*Address correspondence to this author at the Technical University of Denmark - Department of Management Engineering and NCC Construction Denmark A/S Vigerslev Allé 60 3.th, Denmark;

Tel: +45 24887859; E-mail: aku@ncc.dk opportunity to individualize the product he buys at a price closer to that of mass-produced products than that of individually manufactured products $[1,6]$.

The construction industry experiences a need to develop more efficient construction methods in order to compete in a low-margin market, without damaging the architecture of the construction. In order to improve competiveness and margins, it has been typical to focus on standardizing the product [7]. An example is the Chinese company, Broad Group Corporation, which has made great advances in this kind of construction $[8,9]$. In recent years, a new approach has been applied based on mass customization principles [10]. Here, the focus is on the development of integrated system deliveries. This approach has been used for some decades in the manufacturing industry and led to greater margins and market shares for several companies. Mass customization and integrated system deliveries are often used in the manufacturing industry; and successful implementation has created large and complex products. One company that has 


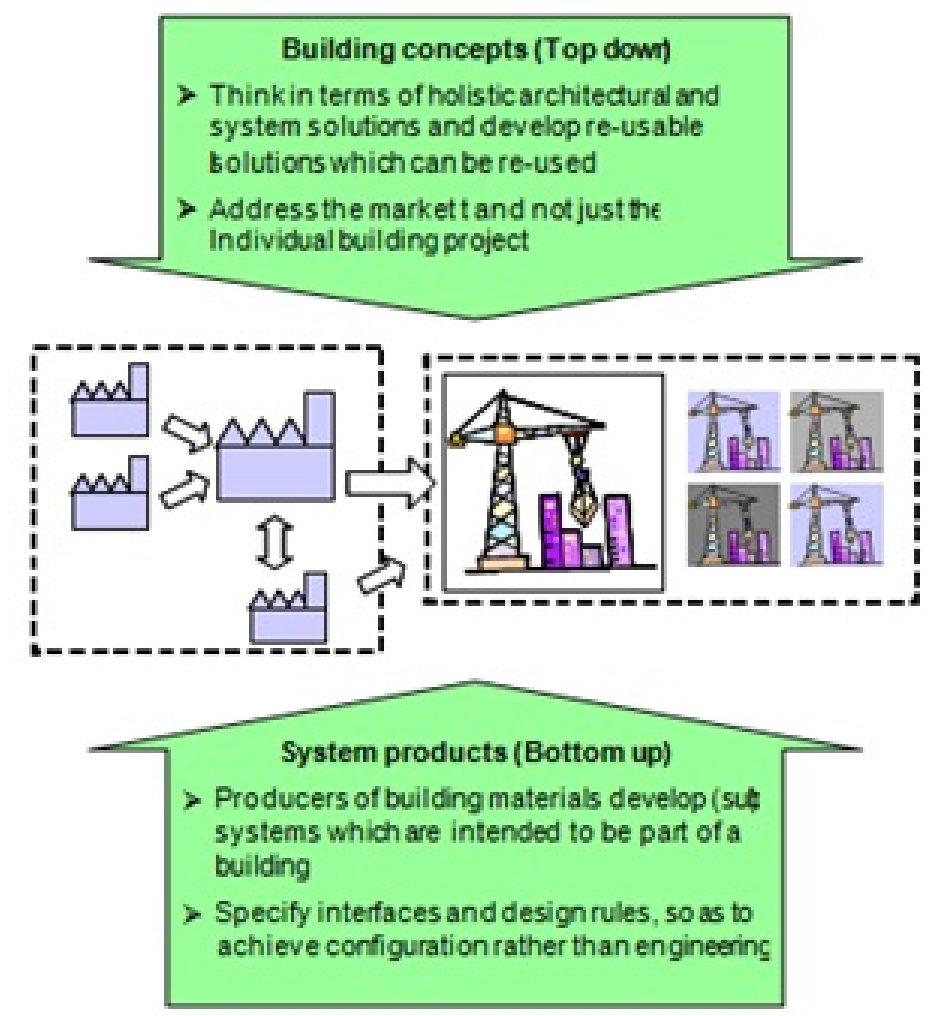

Fig. (1). Top-down vs. bottom-up approach.

succeeded in creating such products and reaped the benefits of mass customization is F.L. Smidth, a leading global producer of cement factories. Through customizing the sales phase, F.L. Smidth has reaped great benefits in the form of short throughput times, more accurate price estimates etc. Through integrated system deliveries, it is possible to differentiate to what degree different components of a construction should be standardized, which enables companies to prioritize and differentiate the level of standardization in each module. Examples of this method exist in the construction industry in Northern Europe. These systems have been developed for office and residential multi-storey constructions and have encompassed entire buildings, often based on prefabrication. Examples of such systems are Skanska AB and IKEA, which developed Boklok (www.boklok.com) and NCC AB (www.ncc.com), which developed NCC Komplett. NCC Komplett was terminated in 2007, however, after five years and a few projects, due to lack of confidence in being able to achieve the construction improvements originally expected. At the time of termination, NCC had invested SEK 1 billion in the project. Since after termination, NCC decided not to discuss the matter further, access to more information is not possible.

\section{BACKGROUND}

For economic and/or political reasons, few companies have been able to develop integrated system deliveries encompassing entire constructions. This inability is mainly due to the huge investments and risks connected with a project of such magnitude. Also, several projects have been tried and failed, which has left potential developers leery about taking up such a challenge (e.g. NCC Komplett).

An alternative to this one-step implementation is to implement gradually, modularizing parts or segments of a construction in order to minimize the scale and economic risk of the project. This gradual implementation can be approached in two ways, either by a top-down or bottom-up approach. In the former approach, the entire building is analyzed, which makes the entire building the product; in the latter approach, a smaller sub-part of the construction is analyzed and modularized, which makes the sub-part the product.

Through a top-down approach, the construction is divided into a few main components and understood in relation to them, which is what F.L. Smidth did in the cement factory construction industry [11]. These components are then further divided into smaller components and so on, until a satisfactory understanding is achieved. This is done on the conceptual level, which means that all the different components are not described in detail - only the larger parts. The example of a car built on a platform can illustrate this. Using the top-down approach, the car is examined and broken down into the chassis, engine, wheels and so on - not going into more detail, but describing these larger parts of the car.

Through the bottom-up approach, the smallest parts and components are examined first and then combined into larger components, the parts of the product, until a satisfactory understanding of the product is achieved. A practical example of this would be a manufacturer that produces solely the locking mechanisms for car doors. The manufacturer re- 
ceives a description of the product explaining in detail what the different components are and what they do. Then, the car manufacturer combines the lock with all the other parts needed, examines and discusses the lock, then the door and so on. This is a continuous analytical process, until the entire car has been analyzed. However, it seldom happens this way in reality; it is only done for smaller parts of the construction. The two principles, bottom-up and top-down, can be used in conjunction; they are not mutually exclusive. They can be used concurrently in such a way that the top-down approach is used to obtain the first overview of the building to find the areas of potential modularization. These areas are then studied using a bottom-up approach (see Fig. 1).

Examining such a complex field as the construction industry using a bottom-up approach would be an exhausting task since it would require examining every single detail of a building, whereas using a top-down approach would make the analysis much more superficial, even though it can be used to locate areas with great potential for modularization.

Buildings are large, complex structures, and they are produced in much smaller quantity than is normally seen in the manufacturing industry. Buildings are the result of compromises between many different stakeholders and their views on many different questions. Thus, an endless number of possible combinations exist that are often chosen on the basis of local traditions or personal taste and subjectivity, and this makes generalization difficult. To describe how it is possible to handle this, an in-depth analysis of two companies was undertaken, one producing balconies and the other installation shafts in apartments.

The balconies are produced by a small Danish company, Altan.dk (www.altan.dk), which controls a network in charge of a production line that manufactures customized balconies for the construction industry. Their aim is to manufacture standardized custom balconies - this is their product. They have used a bottom-up approach to modularization of the building, selected a single product, and standardized its manufacture. The balconies comprise multipart products that have been standardized through the interfaces within the product, since the outer interfaces are relatively unknown. Altan.dk does not focus only on the physical product, the balcony, but the entire process of installation, customer service and support throughout the product's lifetime.

The installation shafts are made by a subsidiary of NCC that delivers customized installation shafts, both internally to NCC's own projects and to external customers. Instead of making the sub-parts/products in situ, the modules are delivered as an integrated module to the construction site; therefore, they only occupy a minimum of space, thus reducing production time significantly. Through this approach, the advantages of a modularization are exploited, the cost of developing modules is divided into smaller segments, and the company can use expert knowledge in the different areas.

\section{THEORY}

Mass Customization - the basic principle of this concept is to create value for the customer by adapting a product to his specific needs. The customer thus perceives that he is receiving a tailor-made product. From the manufacturer's point of view, the product is manufactured from uniform parts that can be produced using a specialized production apparatus; from the customer's point of view, it is a unique product [12].

This means that the idea of customization is to develop a portfolio of products that enables the company to offer the customer what is perceived as a unique product that matches the individual customer's needs. At the same time, the products in the portfolio have a number of common features with respect to design, production and assembly/installation. This means that the products can be considered the same and are therefore easier to produce, assemble and install.

The concept of Mass Customization [1] is embraced by companies that have previously manufactured massproduced and uniform products, and which start to manufacture these products in a continually increasing number of variants, so as to be better able to fulfil their customers' requirements. Or they are companies that have been making individual and unique products, which start producing a specific product or product family with a specified solution space [13].

In order to analyze a product, regardless of whether a bottom-up, top-down or complete modularization approach is used, a product variant master must be used and therefore explained. In order to divide a product into smaller parts and analyze these parts individually, an overview of the existing product range must be made. This overview can be achieved through the use of a Product Variant Master (PVM).

Product Variant Master - the PVM allows the user to map relations between customer wishes, engineering solutions and parts used for a specific product. When a thorough analysis of the product has been carried out, the user will have an extensive overview of the requirements of the market, the technical solutions and the product's sub-systems, along with their correlation with other sub-systems and parts. This correlation is arrived at through the definition of parts as either being 'part-of' other parts or 'kind-of' parts [14]. For a bike, the 'part-of' parts are e.g. the body, wheels, and handlebars (Fig. 2). The 'kind-of' parts are those with several options - e.g. the body frame, for which mountain bike, city bike or classic bike can be chosen. When the different 'part-of's and 'kind-of's are found, different attributes and rules can be created in order to define when and how different parts are related. Frame attributes could be the sizes the frame is available in, or the colours possible to choose from. A rule for the wheels could be that if the front wheel has been chosen to be 20 inches, then the rear wheel has to be 20 inches.

In order to develop and gain the advantages of mass customization, a product can be divided into modules. A module is a sub-system of the product with clearly defined boundaries and interfaces to other modules or the user of the product. It is a standardized part of a product that can be used over and over again [15]. The PVM is a tool that can be used to help decide where and how to define the different modules of a product, since the process of making the overview gives increased knowledge. When a module has been decided upon, it has to be documented, and especially the boundary interaction with other modules must be stated precisely, since this is the way the module connects and interacts with other modules in order to constitute a finished and function- 
ing product. In the construction industry, the ventilation system or the installation shafts could be defined as modules.

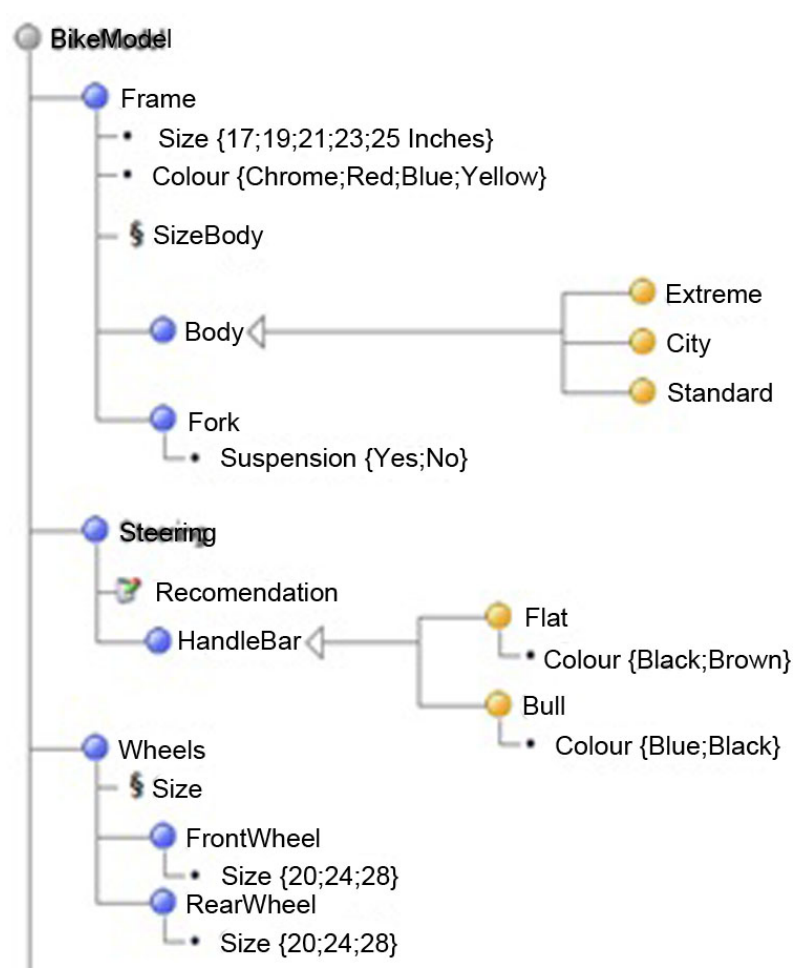

Fig. (2). Product Variant Master example.

After developing these modules, a configuration system can be developed for making customized products while at the same time exploiting the mass customization principles. A configurator is software that defines a solution space for the user, based on rules, attributes and constraints. It allows the user to design products to his needs/demands, while still keeping costs down. The programme is based on options that are restricted by rules and conditions, which in turn are based on binary or $n$-value variables [16]. Binary variables cover - for example if the product is a vehicle - such questions as: Would you like a car or a truck? The n-value variables include such questions as: What colour would you like your vehicle to have? The answers would be yellow, blue, green etc.

These options are then combined with expressions such as 'and', 'or' and 'either or', making it possible to grasp many different options for the product and make a shortlist that can be transferred to a validated design to be used in production. Examples of output benefits would be that the customer experiences that ordering their product is faster, and the seller finds it easier to estimate when the product can be ready for delivery.

Modularized products can be developed in entrepreneurial companies through the application of the mass customization principles. Using these principles to gain insight into the different sub-systems and to find potential areas of integrated system deliveries allows companies to find the areas with the greatest integrated system delivery potential. This approach would alter current construction methods, due to that fact that much construction would be carried out in an intermediate step instead of at the construction site.

\section{METHOD}

In order to obtain some theoretical basis for implementing stepwise modularization in the construction industry, two cases were studied and used as preliminary theory as described in the article, "Building theories from case studies" [17]. The two cases used to gather knowledge that was to be translated into theory were Altan.dk and the construction company NCC Construction A/S' shaft project. Both companies use a bottom-up approach, examining the smaller parts of a construction in order to modularize it. These two cases were studied. Then, the process used was analyzed, and described in the following sections.

One way to look at the construction industry when modularizing it is through a top-down approach, where a construction can be understood through a conceptual view of the standardized technical solutions. The same methods and tools can be used in a very different way when looking at the construction industry from a bottom-up approach. In the topdown approach, an analysis is undertaken by putting the information gathered into a Product Variant Master (PVM), which structures the knowledge so it can be transferred into a configuration system.

The main difference between the two ways of looking at a construction is strongly reflected in the way a PVM is used. Because it is on a more conceptual level, the top-down approach neglects the product part view [1]. The bottom-up approach is much more specific and on a much smaller scale than an entire construction, and here the product part view is integrated into the PVM.

The description and evaluation here is based on the article, "Making product customization profitable" [18], where Mortensen et al. set up four areas that are important for successful product customization. These areas are: Market, Product assortment, Production supply and Organization. The analysis and conclusions in this article are based on, but not fully separated into, these areas, and describe opportunities for and examples of modularization in the construction industry.

\section{ALTAN.DK'S BACKGROUND}

Altan.dk is a company that manufactures balconies. See (Fig. 3). It developed from a small traditional entrepreneur company, Ringsted Bygningsentreprise. They started a modularization project supported by funds from Realdania in which they explored the basis for implementing modules and system deliveries in the construction industry. This proved successful, and in October 2006, Ringsted Bygningsentreprise decided to spin off one of its subsidiaries in the form of Altan.dk. This subsidiary's aim is to manufacture standardized custom balconies - this is their product. They found a market to which they believed they could deliver customized, attractively priced, and high quality balconies for use in construction projects or assemble balconies on already constructed buildings [19].

They used a bottom-up approach to modularizing buildings, found a single construction part, and standardized 


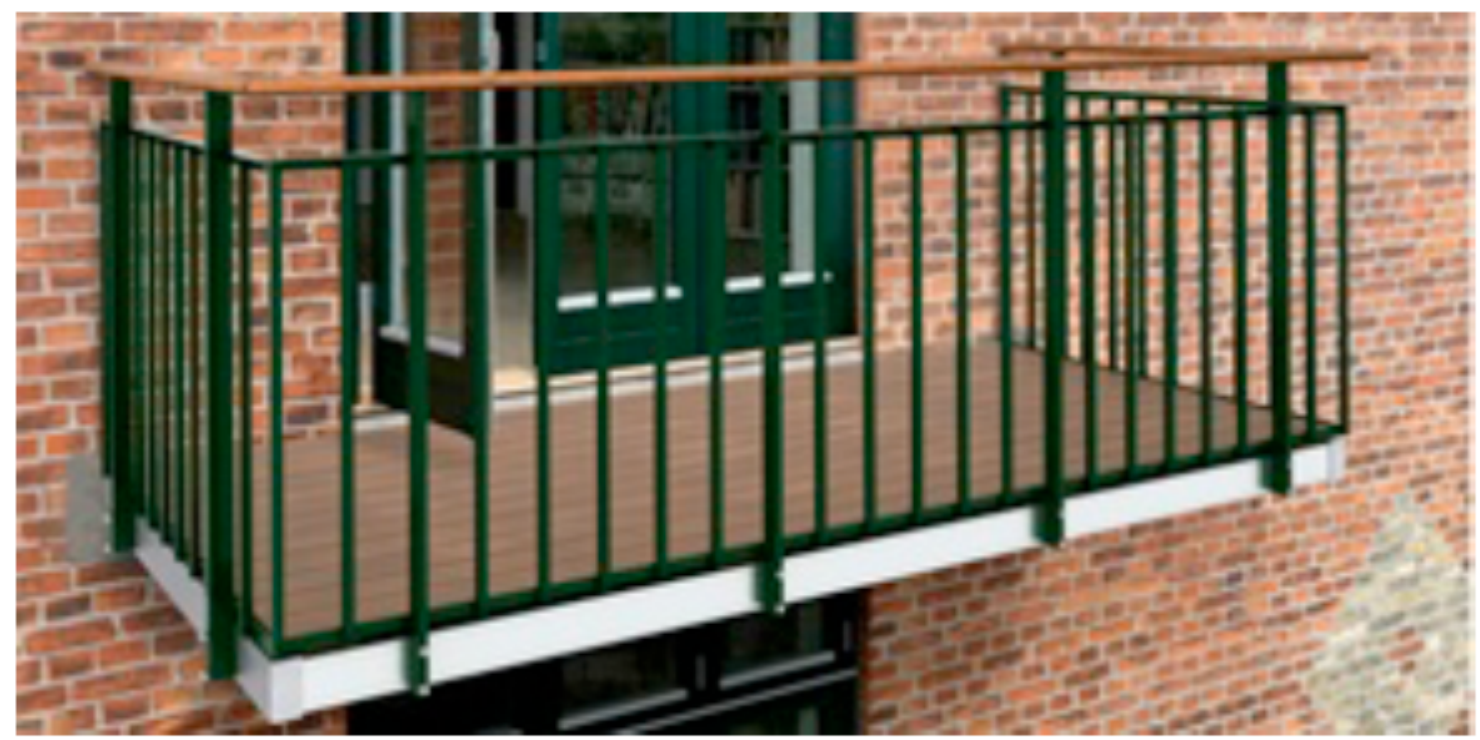

Fig. (3). One of Altan.dk's balconies.

its manufacture and installation. The balconies are multipart products that have been standardized through focus on the interfaces within the product, since the outer interfaces are relatively unknown. Altan.dk focuses not only on the physical part, the balconies, but the entire process, the equipment used for installations, customer service, and lifetime support.

Altan.dk does not manufacture the parts that make up the balcony; they design them and act as middlemen to ensure that suppliers deliver the parts that can then be assembled into a complete balcony. The balcony is installed by one of Altan.dk's specially trained workers.

In order to manufacture more than 2,000 balconies a year, solely for the Danish market, Altan.dk made a PVM to obtain a breakdown of the product list in a user-friendly form. After gaining an understanding of the different parts and rules and manufacturing principles used to construct such a balcony, this knowledge was integrated into a configurator [1].

Before starting the process of development, an interdisciplinary project group was established. The group comprised a specialist from Ringsted Bygningsenterprise (later Altan.dk), static engineers from the consulting engineering company Bascon, configuration system experts and suppliers from 3D Facto, product and product family development consultants from Institute for Product Development (IPU), and the two suppliers of steel and aluminium, Kecon and Weland respectively. One of the main focuses of the development project was reduction and control of variants. By using a PVM, the balconies were separated into two main categories, steel and aluminium. For example, the number of different hole dimensions in the aluminum parts was reduced from 23 to five, and the number of colours was reduced from approximately 40 to ten. These ten colours fulfil approximately 90 percent of the customers' requirements. To make sure that such reductions would not cut off a central part of the market, the company made a number of user surveys. These surveys turned their entire mindset 180 degrees, from an engineering perspective in which the balcony is an external construction part mounted on the building, to a user per- spective in which the balcony is an expansion of the home. This change is very apparent in the company's sales brochure. Before, almost all the pictures were taken from outside - a house with balconies; now, almost all the pictures are taken on the balcony or from inside the home, showing access to the outside [19].

\section{BACKGROUND OF THE NCC SHAFT}

The Danish branch of one of northern Europe's largest construction companies, NCC, developed a prefabricated and configurable installation shaft along with several partners. See (Fig. 4). Today, NCC supplies this prefabricated installation shaft to construction projects both inside and outside the company.

From 2006 to 2008, together with the architectural firm, $\mathrm{RH}$ arkitekter A/S, and the consulting company Valcon Innovation, they developed an integrated system delivery that is a prefabricated installation shaft based on a bottom-up approach. This project was sponsored by the Realdania Foundation, which was very important, because normally contractors, unlike manufacturers, have no tradition for longterm investments in product development.

The reason for starting the project on customizable shafts, but not any other construction parts, is that the shaft is characterized by a relatively intense workload concentrated in a small area, to make a part of the construction that most customers do not care about as long as it works. An analysis at NCC concluded that more than 300 different operations, divided among nine to ten professions, are required in an area of approximately $60 \times 80 \mathrm{~cm}$ with only one access door and harsh working conditions and positions [20].

The main goal of the shaft project was to create a modular shaft to be configured so that it can fit almost any apartment block and be constructed at an off-site plant before being shipped to the construction site and installed. A preassembled solution for the shaft would solve many of the problems often experienced on construction sites. It is also an area that few construction supervisors find interesting to deal with. 


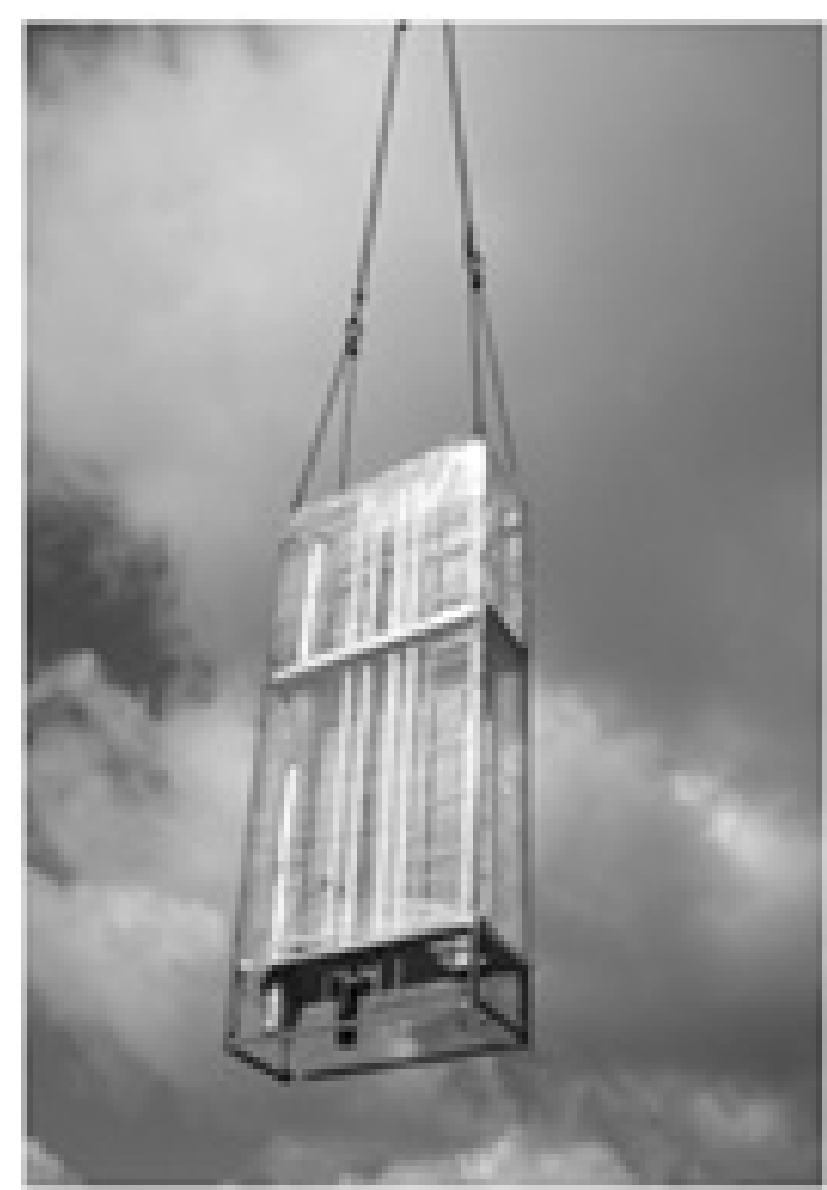

Fig. (4). The NCC Shaft.

Another reason for choosing the shaft as an object for integrated system deliveries is that during the construction design, the architect does not really care about the shaft and just wants it as small as possible so that it does not interfere with the architectural experience of the construction and leaves more space for revenue-generating activities. It is an area that is not supposed to be seen. The architectural experience is important for the customer, because it contributes a lot to the image of the company or to the customer as an individual. When trying to modularize constructions, architecture is often one of the main barriers; however, since shafts are hidden parts of the building that just need to work and not be seen, it functions as a great starting point for developing modules.

As the first step in the development of the shaft, a thorough investigation was carried out in order to define the different interfaces in the existing constructions and their nature. This was done through an investigation of already established buildings. The main aspects in focus were apartment kitchens and bathrooms, which are the two main sources of installations for the shafts. In order to obtain a sufficient amount of data, 24 standard apartments and seven bathroom archetypes were investigated [20].

From the investigation of these archetypes, three shaft designs were made. By using two of them, 80 percent of all the apartments and kitchen archetypes were accounted for; if the third shaft design were used, a staggering 95 percent of the all apartment and kitchen archetypes would be accounted for [20].

When designing these shafts in a modular context, external consultants from the manufacturing industry contributed their experiences with making modules. Inclusion of these external consultants resulted in a solution principle that was based on experiences and methods traditionally used in the manufacturing industry.

The information gathered from the research was broken down and gathered in a PVM. This was done in accordance with three different parts. The first principle is to construct the PVM in such a way that the first part of the PVM showcases the customer's requirements for the different shafts. The different choices made by the customer when ordering a shaft relate to the size, elements and performance of the shaft. The next part of the PVM, the engineering view, describes what the engineers have to know in order to construct a shaft for the construction. The last part of the PVM, the part view, shows all the physical parts of the product, the bolts and nuts.

The choices made in relation to the customer's requirements have some direct effects on the engineering view - for example, if a narrow shaft is chosen, then it has to be outfitted with narrow pipes and tubes. This information is then sent to the product parts list and determines the size of all the pipes and tubes. From this, a complete specification is made of the design and the placement and function of the different interfaces.

\section{MANAGING THE INTERFACES FOR BOTH CASES}

During the development of the modules, the main focus was on the development of internal interfaces between the elements of the product; several external interfaces have therefore not received the same amount of attention. An example of an external interface that was defined is the interface between the shaft and the toilet. This interface was defined so that the toilet would always be situated adjacent to the shaft, thus providing easy access for the necessary installations between the toilet and the shaft. An example of an external interface that is not defined and is therefore left to an individual assessment in each project is the fire-related interfaces - more precisely, the fire-related interfaces connected to assembly, heavy walls, prefabricated bathrooms, and other technical fire-related conditions. The equivalent for Altan.dk is their focus on the internal interfaces, while leaving the external interfaces less defined. This was especially an issue in the earlier phases, and less so when the product matured.

Besides the shaft project and the bottom-up approach, NCC is also developing a "construction concept system" based on a top-down approach, working with the design and decisions made for the entire building. The modular shaft is an integrated part of construction concept development at NCC, and in these projects, these otherwise undefined interfaces - such as the fire requirements - are defined. The reason external interfaces have not been decided on to a greater extent is the lack of documentation for the external modules to which the shaft connects. Due to this lack of documenta- 
tion, there is an imminent need for project-specific interfaces between the shaft and the surrounding modules. Through experience, NCC has discovered that value is only added to the project, if the interfaces are defined after the surroundings have been defined to some extent, which is done in the NCC "construction concept system".

In relation to the entire building, Altan.dk applies stepwise modularization, but in relation to Altan.dk's product, we see a full modularization. In this modularization, Altan.dk has full control of all the internal interfaces of their product, the balcony. The external interface, in terms of the mounting, is also well described and based on five standard solutions; nevertheless, this part needs some project-specific design and calculations, which are performed by the static engineering company, Bascon. Another external interface, which is based on some standard solutions but is not fully standardized, is the access to the balcony. This door, with all its mountings and frames, also needs some degree of projectspecific design.

\section{CONFIGURATION SYSTEMS}

Altan.dk has developed a configurator that contains materials, processes and machinery. Their configurator is only used internally, within the company, which means that there is no direct interaction between the customer and the configuration system. Instead, a salesperson handles the interaction with Altan.dk's customers. The salesperson examines where the balcony is to be located and figures out what the customer actually wants. The customer does not interact directly with the configurator, because unlike a bike, laptop, cell phone etc., a balcony has to be an integrated part of the buildings' architectural appearance - it becomes attached to the side of the apartment building. Also, Altan.dk does not wish to make its solutions and product range public. Since the customer would need a lot of assistance in order to be able to calculate the balcony's location and use the configurator, Altan.dk operates the configurator internally.

NCC wishes to implement a configuration system that would entail both shaft and bathroom, due to the architectural focus. NCC has worked with four different scenarios and has been adamant that the architect must still make the layout decisions related to the areas in question, without having specific knowledge of who and how the final design of the bathroom and shaft will be made. The actual design process is the only thing being modified, and only this process is directly supported by the configuration system. It has been shown that a good and varied range of opportunities exists for using configuration systems in the design of shafts and bathrooms.

\section{EFFECTS FOR BOTH COMPANIES}

Altan.dk and NCC Construction have both implemented modules based on a stepwise modularization using a bottomup approach. The stepwise modularization has given both companies projects that are manageable. Both companies have experienced a change in the way their organizations function: The process has become more streamlined; and with the well-defined product structures, they have obtained a much better overview and more knowledge about their products. This is naturally most significant at Altan.dk, where the new structure embraces the entire product, and where the product is more mature than at NCC.

The use of a configurator at Altan.dk has made it possible to handle tendering, design and planning using fewer people. At the same time, the configurator and its development ensure that all parts of the company know the company's product and name it in the same way, something they have not experienced before.

Through the introduction of modularized shafts, NCC Construction has achieved a more standardized product. This has made the shafts easier to install and lowers the amount of resources needed to create, construct and install the shafts.

The new shaft is a modular installation shaft, which has the advantages of both product customization and mass production. NCC has made a systematic comparison between the in situ shaft and the modular shaft, based on 10 parameters identified as important (Fig. 5).

This shows that the prefabricated shaft offers a number of benefits without costing a lot in long-term flexibility; however, it does decrease especially short-term flexibility, and therefore requires good planning in the early phase. The standard solutions have made this planning much easier, but it is no longer possible to wait and figure out solutions onsite.

\section{DISCUSSION AND CONCLUSION}

\section{Market}

Altan.dk has chosen only to do business directly with the client and does not work as subcontractor. NCC has chosen to sell the shaft as an integrated system delivery to both internal and external projects, thereby also working as a subcontractor. The strategies follow the very different nature of the two products. No end users buy an installation shaft as an individual product, but only as an integrated part of an entire construction. This is in great contrast to the balcony market, where the product is in very direct focus by the end user, and where the replacement or addition of balconies can be the entire project. It can also very easily be separated as an individual project or contract.

\section{Product Assortment}

In relation to the product assortment, the two case companies have made some different choices. Altan.dk has chosen to focus their entire product assortment on a specific part of the market, the balconies. NCC has chosen to modularize a small part of its product assortment and combine it with other strategies, such as concept buildings based on a topdown approach.

Both companies, and especially NCC, have mainly focused on the internal interfaces. The companies have fully described these interfaces to insure optimal production and quality, according to the supported range of the product. The external interfaces are more individual and related to the specific project, and both companies require a certain amount of individual design to handle these interfaces to other construction parts/modules that they cannot fully control. 


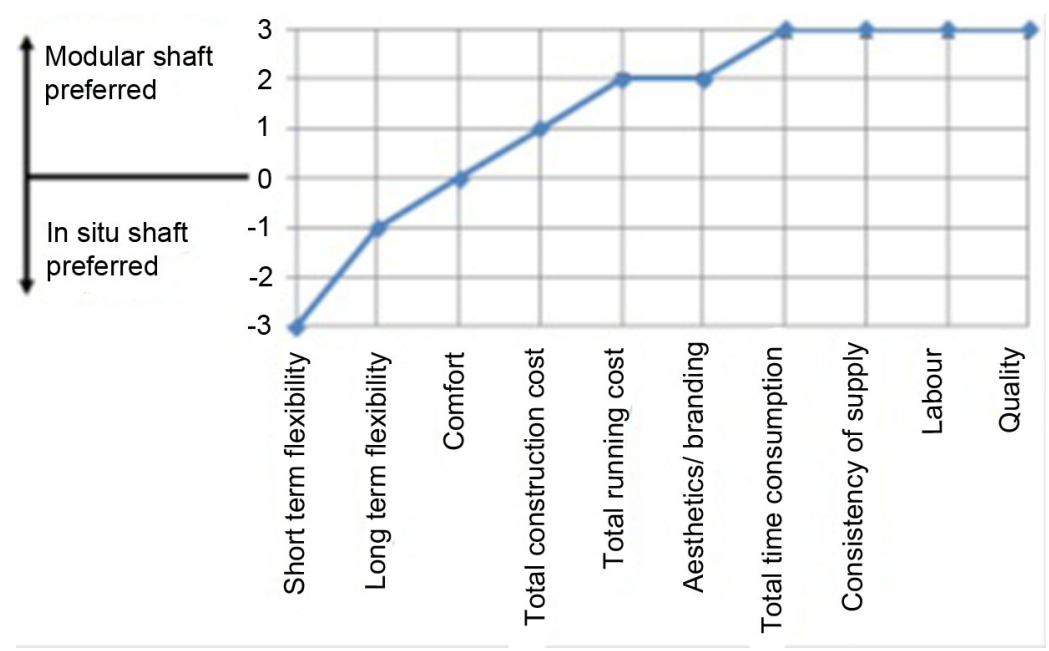

Fig. (5). Different effects from using modularized shafts [18].

The two companies have chosen two different strategies to control product variance. Altan.dk uses direct contact to the customer, to guide the customer in choosing a solution that fulfils his functional and architectural requirements within Altan.dk standard solutions. NCC has chosen a construction part where all the requirements are purely functional; e.g. almost the only relation to the architectural design is the size of the shaft. This gives NCC a product that they only have to optimize and thereby vary according to these functional requirements, a job the designers at NCC can handle pretty independently from the rest of the building design process.

\section{Production Supply}

Both companies have chosen a strategy that is very closely related to their backgrounds as entrepreneurs or contractors. The design is always made by the companies themselves or their strategic partners (Bascon for Altan.dk). None of the companies produce the physical components themselves, but have a number of fixed suppliers to make the components. Altan.dk always does the onsite montage, while NCC normally does the onsite montage on their own projects, but lets the customer do it on external projects. Thereby, NCC's role is more that of a construction product supplier, while Altan.dk maintains a close relationship to the client.

\section{Organization}

Altan.dk has most purely placed itself as the head of the entire organization, from sale to post-sale. Altan.dk does not perform all the functions itself, but they are in control of the entire organization. NCC has focused precisely on a general change in the way construction projects are organized. It has changed its roll from that of contractor with solutions designed by architects and engineering companies, to that of system supplier that designs the solutions.

\section{Overall Conclusion}

The cases show that a number of benefits can be gained through implementation of modules in the construction in- dustry. This was done by focusing on a bottom-up approach to a product, i.e. by describing one specific part of a construction in great detail. This was done in order to optimize a smaller part of a construction, neglecting the rest. In this way, the companies have gained a substantial amount of information and been able to handle it.

In addition, focus was partly on parts of a construction. In the case of NCC Construction, this is a part that has no direct impact on the end user, at least no impact they are aware of. Altan.dk, on the other hand, works as an organizing unit. They install the balconies themselves and are in charge of organizing the construction; but they are not in charge of manufacturing the balconies. They have their configuration system within the company - the customer does not see it - and pull strings through their subcontractors. One reason for not letting the customer perform the work on the configurator is that they can use the configurator and then hire another company to do the work. The use of a configurator has proven beneficial for Altan.dk, because they can easily see what has to be done and which strings they should pull.

Through the case studies, we see that it is possible to streamline the processes that go into making parts of a construction. This has been done through choosing a few different tools that allow employees in charge of the analytical work to gather substantial knowledge about the company's product range. Both Altan.dk and NCC Construction have done this through the use of a PVM. With this tool, they have gathered all relevant information about the product range - parts, rules, constraints and attributes - and then used this information to map the companies' actual products. The gathered information was then analyzed and has led to the construction of configurators that takes all the information, in addition to input from a salesperson in cooperation with a customer, and performed a calculation of what is needed to fulfil the requirements. This is then showcased for the customer and processed through the company, so that production of the specific product can begin. 


\section{CONFLICT OF INTEREST}

The author(s) confirm that this article content has no conflicts of interest.

\section{ACKNOWLEDGEMENT}

Declared none.

\section{REFERENCES}

[1] L. Hvam, N. H. Mortensen, and J. Riis, Product Customization, Springer: Berlin, Heidelberg, 2008.

[2] A. Joneja, and N. K.S. Nevilli, "Automated configuration of parametric feeding tools for mass customization", Computers and Industrial Engineering, vol. 35, pp. 463-466, 1998.

[3] V.B. Kreng, and T. Lee, "Modular product design with grouping genetic algorithm-a case study", Computers and Industrial Engineering, vol. 46, pp. 443-460, 2004.

[4] L. Hvam, "The Rulers Factory - a tool for learning product modeling techniques", Computers and Industrial Engineering, vol. 35, pp. 29-32, 1998.

[5] J. Jiao, M.M. Tseng, M. Mitchell, V.G. Vincent, and F. Lin, "Product family modeling for mass customization", Computers and Industrial Engineering, vol. 35, pp. 495-498, 1998.

[6] F. Salvador, P.M. De Holan, and F. Piller, "Cracking the code of mass customization", MIT Sloan Management Review, vol. 50, pp. 71, 2009.

[7] S. Bertelsen, "Bellahoej Ballerup Broendby strand - 25 aar der industrialiserede byggeriet", Statens Byggeforskningsinstitut: Hoersholm, 1997.

[8] M.I. Arshad, " Automated Horizontal Building Construction - A new Paradigm", Proceedings of the CIB IAARC W119 Workshop, 2012, pp. 6-16.

[9] Reference: Available from: http://thefabweb.com/16814/a-chinesemiracle-30-storey-hotel-in-15-days/\#.UEyiFY3ia6M [Accessed July 17, 2013].
[10] D. Benros, and J.P. Duarte, "An integrated system for providing mass customized housing", Automation in Construction, vol. 18, pp. 310-320, 2009 .

[11] L. Hvam, "Mass customization of process plants", International Journal of Mass Customization, vol. 1, pp. 445-462, 2006.

[12] B.J. Pine, "Mass customization - the New Frontier in Business Competition", Harvard Business School Press: Boston, 1993.

[13] C.L. Thuesen, and C.C. Claeson, "The Long Tail and Innovation of New Construction Practices: Learning Points from Two Case Studies", In: Open Building Manufacturing Key Technologies, Applications, and Industrial Cases, A.S. Kazi, M. Hannus, S. Boudjabeur, Manubuild, 2009, pp. 49-64.

[14] U. Harlou, "Developing product families based on architectures", $\mathrm{Ph}$. D. thesis, Technical University of Denmark, Lyngby, June 2006.

[15] A. Ericsson, and G. Erixon, "Controlling design variants - modular product platforms", Society of Manufacturing Engineers, Dearborn, 1999.

[16] R.W. Bourke, "Configurators: A Status Report", APICS - the Performance Advantage - American Production and Inventory Control Society, USA, vol. 8, pp. 42, 1998.

[17] K.M. Eisenhardt, "Building theories from case study research", Academy of Management Review, vol. 14, pp. 532-550, 1989.

[18] N.H. Mortensen, L. Hvam, P. Boelskifte, C. Lindschou, S, Frobenius, and A. Haug, "Making product customization profitable", International Journal of Industrial Engineering: Theory Applications and Practice, vol. 17, pp. 25-35, 2010.

[19] Building lab dk, "Ud i det blaa - En innovationshistorie om Altan.dk", Reference: Available from: http://www.dac.dk/ media/9659/BI_altanrapport_240807_LOW.pdf, 2007 [Accessed July $18,2013]$.

[20] Building lab dk, "Paa vej mod fremtidens skakt - En innovationshistorie om praefabrikerede installationsskakte til etageboliger", Reference: Available from: http://www.dac.dk/media/ 9657/skakten-rapport_19-korrektur.pdf, 2008 [July 18, 2013].

Received: August 20, 2013

Revised: August 25, 2013

Accepted: August 26, 2013

(C) Kudsk et al.; Licensee Bentham Open.

This is an open access article licensed under the terms of the Creative Commons Attribution Non-Commercial License (http://creativecommons.org/licenses/by-nc/3.0/) which permits unrestricted, non-commercial use, distribution and reproduction in any medium, provided the work is properly cited. 